\title{
STUDY ON EFFECT OF QUADRICEPS MUSCLE RESISTANCE TRAINING ON CARDIORESPIRATORY PARAMETERS IN YOUNG HEALTHY FEMALES
}

\author{
SUDEEP KALE*, MUNIRA Y MANDSAURWALA, MEDHA DEO \\ Department of Physiotherapy, Terna Physiotherapy College, Sector 12, Nerul (West) Navi Mumbai, Maharashtra, India. Email: \\ sudeepkale@gmail.com
}

Received: 09 April 2021, Revised and Accepted: 15 May 2021

\begin{abstract}
Objective: The objectives of the study were to determine and compare acute changes in the cardiorespiratory parameters in young, healthy females in response to 3 weeks resistive exercises to quadriceps muscle using DeLorme's and MacQueen's protocol.

Methods: The study was carried in 30 young, healthy females aged 18-25 years. Resting blood pressure measured in systole blood pressure (SBP), blood pressure measured in diastole diastolic blood pressure (DBP), respiratory rate (RR), and heart rate (HR) were measured. Subjects were then divided randomly into two groups containing 15 subjects in each group. Ten repetition maximum was measured for each subject. Group A subjects were given resistive exercises for the quadriceps muscle bilaterally using DeLorme's protocol and Group B subjects were given training with MacQueen's protocol. In both groups, training was given thrice a week for 3 weeks.
\end{abstract}

Results: SBP, HR, and RR showed significant statistical differences after 3 weeks of PRE using DeLorme's protocol; however, DBP changes were non-significant. SBP, HR, RR, and DBP showed significant statistical difference after 3 weeks of PRE using MacQueen's protocol. In a comparison of DeLorme's protocol and MacQueen's protocol, a significant statistical difference in parameters of SBP and HR was observed. Improvement was more in subjects trained with MacQueen's protocol.

Conclusion: The resistive training has beneficial effects on HR, systolic SBP, and RR. MacQueen protocol is more effective than DeLorme's protocol. Hence, resistive training should be included in an exercise program.

Keywords: Resistive training, Cardiorespiratory effects, DeLorme’s protocol, MacQueen protocol.

(C) 2021 The Authors. Published by Innovare Academic Sciences Pvt Ltd. This is an open access article under the CC BY license (http://creativecommons.org/ licenses/by/4.0/) DOI: http://dx.doi.org/10.22159/ajpcr.2021v14i6.41697. Journal homepage: https://innovareacademics.in/journals/index.php/ajpcr

\section{INTRODUCTION}

The mortality and morbidity associated with cardiovascular diseases (CVDs) are increasing day by day. CVD is becoming one of the major causes of mortality in India [1]. In the Indian population, the age of onset of cardiac disease is earlier than in the Western population $[2,3]$. The risk of ST-segment elevated myocardial infarction in persons with cardiac diseases is increasing [4]. Adherence to lifestyle changes, exercises is one of the important aspects to manage cardiac diseases [5]. Cardiac rehabilitation services are becoming popular day by day in India. The references to physiotherapy departments for cardiac rehabilitation are increasing. Cardiac rehabilitation programs traditionally focus on aerobic training [6].

Progressive resistance exercises (PRE) are a form of exercise in which opposing load is applied to the muscle and increased progressively with the help of mechanical devices. The training is given with the use of repetition maximum (RM). PRE is commonly used for strengthening skeletal muscles and is prescribed for conditioning muscles [7]. DeLorme's and MacQueen's protocols are commonly used PRE protocols. The effect of resistive training with DeLorme's and MacQueen's protocol on muscle strength and endurance is studied [8]. There is a dearth of studies investigating the effects of these protocols on cardiorespiratory parameters.

The literature published in this area is mostly focused on effects on muscle strength and endurance on a long-term basis $[9,10]$. The quadriceps muscle is commonly affected in chronic cardiorespiratory patients. The literature highlights that the acute effects of PRE on the cardiorespiratory system have not been studied adequately. The current study aimed to determine the acute physiological effects of the resistance training program on various cardiovascular parameters.
As a result, the purpose of this study was to determine and compare acute changes in cardiorespiratory parameters in young, healthy females in response to 3 weeks of quadriceps muscle resistive exercises using DeLorme's and MacQueen's protocols.

\section{METHODS}

Type of study - experimental.

Sampling technique: Simple random sampling.

Place of study: Mumbai.

Inclusion Criteria: Young healthy females between the ages of 18 and 25 .

Exclusion Criteria - Females having cardiac, respiratory diseases such as ischemic heart disease, asthma, chronic bronchitis, and emphysema, subjects performing any form of exercises.

Outcome measures - systole blood pressure (SBP), diastolic blood pressure (DBP), respiratory rate (RR), and heart rate (HR).

Thirty subjects were selected as per the inclusion criteria. The written consent was taken from each subject participating in the study. The ethical approval was taken from the institutional ethical committee. Cardiorespiratory parameters of resting systolic blood pressure, $\mathrm{HR}$, and respiratory rate were measured. Subjects were then divided randomly into two groups containing 15 subjects in each group. $10 \mathrm{RM}$ was derived for each subject.

Group A subjects were given resistive exercises for the quadriceps muscle bilaterally using DeLorme's protocol thrice a week for 3 weeks. Three sets of 10 repetitions with $90 \mathrm{~s}$ pause in between were given. Group B subjects were given resistive exercises for the quadriceps muscle bilaterally using MacQueen's protocol thrice a week for 3 weeks. 
Four sets of 10 repetitions with $90 \mathrm{~s}$ pause in between were given. DeLorme's protocol incorporated 3 sets of 10RM with the increasing load during each set, that is, $50 \%$ of $10 \mathrm{RM}, 75 \%$ of $10 \mathrm{RM}$, and $100 \%$ of 10 RM. MacQueen's protocol incorporated four sets of 10 repetitions with $100 \%$ resistance of $10 \mathrm{RM}$ in each set. Both the protocols incorporated a rest interval between sets and determined $10 \mathrm{RM}$ of each muscle before prescribing exercises.

10 RM was measured after each week and progressed accordingly for all the subjects. Parameters of SBP, DBP, HR, and RR rate were then measured after 3 weeks of training and changes in cardiorespiratory parameters were recorded.

\section{RESULTS}

The mean SD was derived from descriptive statistics. The paired t-test was used to measure differences between groups, whereas the unpaired t-test was used to compare both protocols. In group A, SBP, HR, and RR showed significant statistical differences after 3 weeks of PRE using DeLorme's protocol, whereas DBP was non-significant (Table 1 and Fig. 1). In group B, SBP, HR, RR, and DBP showed significant statistical difference after 3 weeks of PRE using MacQueen's protocol. (Table 2 and Fig. 2). In comparison to groups $A$ and $B$, there was a significant statistical difference in parameters of systolic blood pressure and HR (Table 3 and Fig. 3). Group B improved the most.

\section{DISCUSSION}

The current study was designed to investigate and compare the effectiveness of DeLorme's and MacQueen's protocol on cardiorespiratory parameters by giving resistive exercises to quadriceps muscle bilaterally in young, healthy females between the age group of 18 and 25 years. Significant improvements in SBP and HR were observed after a 3-week training program with DeLorme's protocol. However, no effect on DBP was observed in training with DeLorme's protocol. All the parameters have shown significant improvement with MacQueen's protocol. The training with MacQueen's protocol showed more effective results than training with DeLorme's protocol.

Table 1: Comparison of pre and post cardiorespiratory parameters of subjects following DeLorme's protocol

\begin{tabular}{|c|c|c|c|c|c|}
\hline $\begin{array}{l}\text { Cardiorespiratory } \\
\text { parameters }\end{array}$ & $\begin{array}{l}\text { Mean } \\
\text { value } \\
\text { Pre }\end{array}$ & $\begin{array}{l}\text { Mean } \\
\text { value } \\
\text { Post }\end{array}$ & p value & t value & Result \\
\hline $\begin{array}{l}\text { Systole blood } \\
\text { pressure }\end{array}$ & 124.26 & 122.9 & 0.0009 & 4.183 & \\
\hline $\begin{array}{l}\text { Diastolic blood } \\
\text { pressure }\end{array}$ & 81.73 & 81.33 & 0.824 & 1.871 & $\begin{array}{l}\text { Not } \\
\text { significant }\end{array}$ \\
\hline Heart rate & 70.2 & 68.13 & $<0.0001$ & 10.020 & $\begin{array}{l}\text { Extremely } \\
\text { significant }\end{array}$ \\
\hline Respiratory rate & 18.8 & 18.26 & 0.0061 & 3.228 & $\begin{array}{l}\text { Very } \\
\text { significant }\end{array}$ \\
\hline
\end{tabular}

Table 2: Comparison of pre and post cardiorespiratory parameters of subjects following MacQueen's protocol

\begin{tabular}{|c|c|c|c|c|c|}
\hline $\begin{array}{l}\text { Cardiorespiratory } \\
\text { parameters }\end{array}$ & $\begin{array}{l}\text { Mean } \\
\text { value } \\
\text { post }\end{array}$ & $\begin{array}{l}\text { Mean } \\
\text { value } \\
\text { post }\end{array}$ & $p$ value & t value & Result \\
\hline $\begin{array}{l}\text { Systole blood } \\
\text { pressure }\end{array}$ & 122.93 & 120.26 & $<0.0001$ & 8.367 & $\begin{array}{l}\text { Extremely } \\
\text { significant }\end{array}$ \\
\hline $\begin{array}{l}\text { Diastolic blood } \\
\text { pressure }\end{array}$ & 86.23 & 85.24 & 0.0201 & 2.582 & Significant \\
\hline Heart rate & 69.46 & 66.4 & $<0.0001$ & 16.877 & $\begin{array}{l}\text { Extremely } \\
\text { significant }\end{array}$ \\
\hline Respiratory rate & 18.6 & 18.13 & 0.0035 & 3.50 & $\begin{array}{l}\text { Very } \\
\text { significant }\end{array}$ \\
\hline
\end{tabular}

The exercises have been found to increase the function of the cardiac system. The resistance offered during exercises stimulates the cardiac muscle to contract strongly. This increases the left ventricular wall thickness, the mass of the left ventricle and septum [11]. These factors increase cardiac output and stroke volume. An increase in these parameters subsequently reduces the HR.

The oxygen demand increases during exercises. The blood circulation to working muscle is increased during exercises. The impulse is generated by the sinoatrial node (SA node). The changes in HR are affected by factors that affect the SA node. The parasympathetic and sympathetic nervous systems regulate the HR. After resistance training for at least 3-5 weeks, there is a reduction in the sympathetic tone and parasympathetic inhibition at rest, which reduces the HR at rest.

MacQueen's protocol has proved to be more effective than DeLorme's because of the intensity of training. MacQueen's protocol consists of

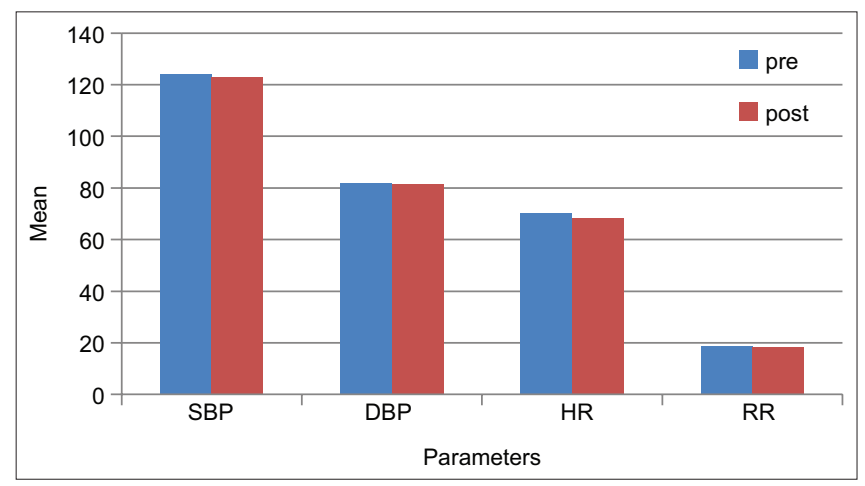

Fig. 1: Comparison of cardiorespiratory parameters of subjects following DeLorme's protocol

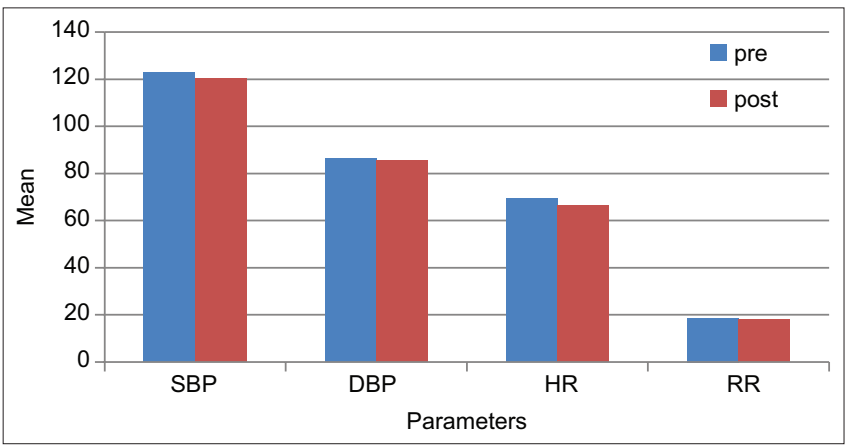

Fig. 2: Comparison of cardiorespiratory parameters of subjects following MacQueen's protocol

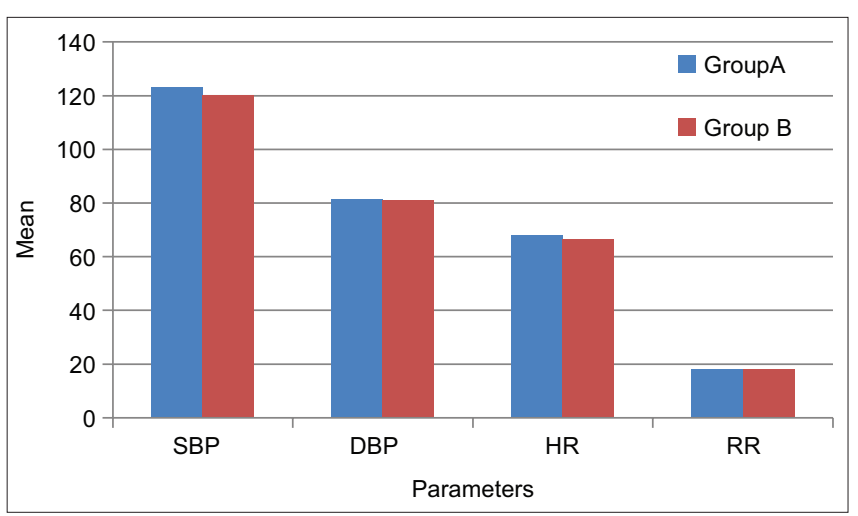

Fig. 3: Comparison of DeLorme's and MacQueen's protocol cardiorespiratory parameters of subjects 
Table 3: Comparison of DeLorme's and MacQueen's protocol cardiorespiratory parameters of subjects

\begin{tabular}{lllll}
\hline Cardio-respiratory parameters & Group A DeLorme's & Group B MacQueen's & p value & t value \\
\hline Systole blood pressure & 122.93 & 124.26 & 0.0149 & 2.594 \\
Diastolic blood pressure & 86.23 & 81.73 & 0.5819 & 0.5571 \\
Heart rate & 69.46 & 70.2 & Significant & Not significant \\
Respiratory rate & 18.6 & 18.8 & 0.0317 & 2.262 \\
\hline
\end{tabular}

$100 \%$ of 10 RM in all 4 sets, whereas DeLorme's protocol consists of $50 \%$ of RM in the $1^{\text {st }}$ set, $75 \%$ of RM in the $2^{\text {nd }}$ set, and $100 \%$ of RM in the $3^{\text {rd }}$ set. MacQueen's protocol consists of 4 sets of 10 repetitions, whereas DeLorme's consists of 3 sets of 10 repetitions. The increased intensity and repetitions achieved better results in training with MacQueen protocol.

The results of our study were supported by the findings of other studies [12-16]. A significant reduction in SBP was noted after 4 sessions of resistance training [11]. Combining resistance training with traditional training lowered the SBP [17]. Similar results were observed after 4 weeks of resistance training in pre-hypertensive patients who have reported lowered blood pressure [12].

\section{CONCLUSION}

Resistive training has beneficial effects on cardiorespiratory parameters. The MacQueen protocol is more effective than DeLorme's protocol. Hence, resistive training should be included in the exercise program.

\section{FUNDING ACKNOWLEDGMENT}

No external funding.

\section{CONFLICTS OF INTEREST}

We have no conflicts of interest to declare.

\section{AUTHORS' CONTRIBUTION STATEMENT}

Dr. Munira presented and conceived idea, collected data, and performed the computations. Dr. Sudeep developed the theory, improvised the research framework and supervised the work, and drafted the manuscript. Dr. Medha assisted in refining the work and manuscript. All authors discussed the results and contributed to the final manuscript.

\section{REFERENCES}

1. India State-Level Disease Burden Initiative CVD Collaborators. The changing patterns of cardiovascular diseases and their risk factors in the states of India: The Global burden of disease study 1990-2016. Lancet Glob Health 2018;6:e1339-51.

2. Reddy KS, Shah B, Varghese C, Ramadoss A. Responding to the threat of chronic diseases in India. Lancet 2005;366:1744-9.

3. Prabhakaran D, Singh K, Roth GA, Banerjee A, Pagidipati NJ, Huffman MD. Cardiovascular diseases in India compared with the
United States. J Am Coll Cardiol 2018;72:79-95.

4. Singh SP, Rajender M. A prospective observational study on risk assessment of stemi patients at a tertiary care hospital. Int J Pharm Pharm Sci 2015;7:148-53. Available from: https://www.innovareacademics. in/journals/index.php/ijpps/article/view/3448. [Last accessed on 2021 Apr 27].

5. Elbur AI. Level of adherence to lifestyle changes and medications among male hypertensive patients in two hospitals in Taif; Kingdom of Saudi Arabia. Int J Pharm Pharm Sci 2015;7:168-72. Available from: https://www.innovareacademics.in/journals/index.php/ijpps/article/ view/4804. [Last accessed on $2021 \mathrm{Apr} 27$ ]

6. Babu AS, Turk-Adawi K, Supervia M, Jimenez FL, Contractor A, Grace SL. Cardiac rehabilitation in India: Results from the international council of cardiovascular prevention and rehabilitation's global audit of cardiac rehabilitation. Glob Heart 2020;15:28.

7. Daşkapan A, Tonga E, Duruturk N, Tuzun EH. Effects of two different quadriceps strengthening exercise approaches on cardiovascular fitness in healthy female subjects: A single blind randomized study. J Back Musculoskelet Rehabil 2012;25:81-7.

8. Fish DE, Krabak BJ, Johnson-Greene D, DeLateur BJ. Optimal resistance training: Comparison of DeLorme with Oxford techniques. Am J Phys Med Rehabil 2003;82:903-9.

9. Pantelic S, Popovic M, Miloradovic V, Kostic R, Milanovic Z, Bratic M. Effects of short-term exercise training on cardio respiratory fitness of male adults with myocardial infarction. J Phys Ther Sci 2013;25:929-35.

10. Chaudhary S, Kang MK, Sandhu JS. Effects of aerobic versus resistance training on cardiovascular fitness. Asian J Sports Med 2010;1:177-84.

11. Stone MH, Wilson GD, Blessing D, Rozenek R. Cardiovascular responses to short-term Olympic style weight-training in young men. Can J Appl Sport Sci 1983;8:134-9.

12. Mohebbi H, Rahmani-Nia F, Sheikholeslami D, Faraji H. Effect of exercise intensity and volume resistance on blood pressure, heart rate, myocardial oxygen cost of subsequent activities. Med Sci J Islamic Azad Univ Mashhad 2009;5:27-34.

13. Berent R, von Duvillard SP, Crouse SF, Sinzinger H, Green JS, Schmid P. Resistance training dose response in combined endurance-resistance training in patients with cardiovascular disease: A randomized trial. Arch Phys Med Rehabil 2011;92:1527-33.

14. Schwartz RS, Hirth VA. The effects of endurance and resistance training on blood pressure. Int J Obes Relat Metab Disord 1995;19 Suppl 4:S52-7.

15. Kelley GA, Kelley KS. Progressive resistance exercise and resting blood pressure: A meta-analysis of randomized controlled trials. Hypertension 2000;35:838-43.

16. Anderson L, Oldridge N, Thompson DR, Zwisler AD, Rees K, Martin N, et al. Exercise-based cardiac rehabilitation for coronary heart disease: Cochrane systematic review and meta-analysis. J Am Coll Cardiol 2016;67:1-12.

17. Scheuer J, Tipton CM. Cardiovascular adaptations to physical training. Annu Rev Physiol 1977;39:221-51. 